\title{
Fabrication and Characterization of Porous Non-Woven Carbon Based Highly Sensitive Gas Sensors Derived by Magnesium Oxide
}

\author{
Yesol Kim ${ }^{1}$, Seho Cho ${ }^{1}$, Sungho Lee ${ }^{2}$ and Young-Seak Lee ${ }^{1, *}$ \\ ${ }^{1}$ Department of Fine Chemical Engineering and Applied Chemistry, BK21-E²M, Chungnam National University, Daejeon 305-764, \\ Korea \\ ${ }^{2}$ Institute of Advanced Composites Materials, Korea Institute of Science and Technology, Jeonbuk 565-902, Korea
}

\section{Article Info}

Received 8 August 2012

Accepted 28 September 2012

*Corresponding Author

E-mail: youngslee@cnu.ac.kr Tel: $+82-42-821-7007$

\section{Open Access}

DOI: http://dx.doi.org/

10.5714/CL.2012.13.4.254

This is an Open Access article distributed under the terms of the Creative Commons Attribution Non-Commercial License (http://creativecom mons.org/licenses/ by-nc/3.0/) which permits unrestricted non-commercial use, distribution, and reproduction in any medium, provided the original work is properly cited.

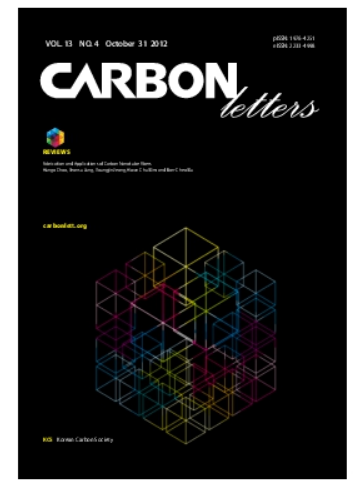

http://carbonlett.org

pISSN: 1976-4251

elSSN: 2233-4998

Copyright $\odot$ Korean Carbon Society

\begin{abstract}
Nanoporous non-woven carbon fibers for a gas sensor were prepared from a pitch/polyacrylonitrile (PAN) mixed solution through an electrospinning process and their gas-sensing properties were investigated. In order to create nanoscale pores, magnesium oxide $(\mathrm{MgO})$ powders were added as a pore-forming agent during the mixing of these carbon precursors. The prepared nanoporous carbon fibers derived from the $\mathrm{MgO}$ pore-forming agent were characterized by scanning electron microscopy (SEM), $\mathrm{N}_{2}$-adsorption isotherms, and a gassensing analysis. The SEM images showed that the $\mathrm{MgO}$ powders affected the viscosity of the pitch/PAN solution, which led to the production of beaded fibers. The specific surface area of carbon fibers increased from 2.0 to $763.2 \mathrm{~m}^{2} / \mathrm{g}$ when using this method. The template method therefore improved the porous structure, which allows for more efficient gas adsorption. The sensing ability and the response time for the NO gas adsorption were improved by the increased surface area and micropore fraction. In conclusion, the carbon fibers with high micropore fractions created through the use of $\mathrm{MgO}$ as a pore-forming agent exhibited improved NO gas sensitivity.
\end{abstract}

Key words: carbon fibers, electrodes, electrospinning, gas sensor, porous carbon

\section{Introduction}

A number of chemical pollutants, many of which are released from chemical plants and automobiles, have become global environmental issues. Therefore, effective measures for the treatment of flue gases should be taken to limit pollution from exhaust [1]. Among these gases, nitric oxide, which is produced during burning processes, reacts with ozone in the atmosphere to form nitrogen dioxide. The nitrogen dioxide then combines with water to form nitrous and nitric acids, which cause acid rain. In addition, nitric oxide has an injurious influence on hum an health and the environment. Hence, the development of a NO gas sensor for the measurement of $\mathrm{NO}$ levels would aid in the monitoring and reduction of the release of NO [2-4]. Gas sensors have been considered promising alternatives for the measurement of environmental pollutants due to their low cost, high sensitivity, fast response and direct electronic interface. However, the performance of these sensors, including their accuracy, selectivity and reliability, must be improved to satisfy the requirements for standard air pollution measurement [5]

Metal oxide semiconductors have been used as gas-sensing materials due to their high responsiveness to target gases [6]. Metal oxide gas sensors have the greatest potential due to their very low cost, high sensitivity, fast response/recovery time, simple electronic interface, ease of use, low maintenance, and ability to detect a large number of gases [7]. However, these sensors require a high operational temperature, which severely limits their potential use [8]. 
The development of gas sensors using carbon materials has been studied by many researchers. Carbon materials are used in many electrochemical applications due to their advantageous electrical and thermal conductivities, low density, adequate corrosion resistance, low thermal expansion, low elasticity and high purity [9]. In addition, a number of carbonbased materials, which include activated carbon, single- and multi-carbon nanotubes, graphite, graphite nanofibers, fullerenes and whiskers, have been developed over the last few decades. Among these materials, carbon nanofibers generally have useful tensile properties, low densities, and high thermal and good chemical stability in the absence of oxidizing agents, good thermal and electrical conductivity levels, and excellent creep resistance.

Carbon fibers are manufactured from two main sources: polyacrylonitrile (PAN) and petroleum pitch (or mesophase pitch). Two general approaches can be used to enhance the graphitization of a pitch-based precursor. The graphitic structure gives pitch-based carbon fibers a higher elastic modulus and higher thermal and electrical conductivity levels along the direction of the fiber $[10,11]$. However, pitch-based fibers exhibit poor electrospinnability due to their low molecular weight and low solubility in solvents such as tetrahydrofuran (THF) and dimethylformamide (DMF). These limitations can be improved through the blending of the carbon fibers with a polymer with improved electrospinning ability, such as PAN. Therefore, we reasoned that carbonized pitch/PAN blends might combine the excellent fiber-forming ability of PAN and the conductivity of pitch to create a promising electrode material [12].

One of the methods currently used to prepare microporous and mesoporous carbon is known as the template method. Template methods are advantageous due to the homogenous size and morphology of the micropores and mesopores that are formed, even in an ordered state. Therefore, this process was used in this study for the preparation of nanoporous carbon fibers, using magnesium oxide $(\mathrm{MgO})$ as a pore-forming agent. We developed a new method for the preparation of nanoporous carbon fibers that does not require the use of any activation processes $[13,14]$.

In this study, nanoporous non-woven carbons fibers with a narrow pore size for gas-sensing electrodes were prepared from electrospun pitch/PAN fibers using $\mathrm{MgO}$ powders. The effects of different content ratios of the $\mathrm{MgO}$ additives on the sensitivity and response time of the resultant $\mathrm{NO}$ gas sensor were investigated.

\section{Experimental}

\subsection{Materials}

The petroleum-derived isotropic pitch was obtained through the condensation of pyrolyzed fuel oil (Hanwha Chemical Co., Korea). PAN (molecular weight $=160,000$, Aldrich Chemical Co., USA) was used as a carbon source. THF and DMF $(\geq 99.9 \%$ ) (Aldrich Chemical Co., USA) were used as solvents. These solvents were used without further purification. $\mathrm{MgO}$ (Aldrich Chemical Co., $<10 \mathrm{~nm}$ ) was used as a pore-forming agent to form the porous structure

\subsection{Preparation of electrospun pitch/PAN- based carbon fibers}

The concentration of the pitch in the THF was $20 \mathrm{wt} \%$. A $14 \mathrm{wt} \%$ solution of PAN in DMF was added to the pitch in the THF solution with a pitch/PAN solution weight ratio of $7 / 3$. The pitch/PAN solution was impregnated with $\mathrm{MgO}$ at PANbased content ratios of 10,25 , and $50 \mathrm{wt} \%$ [15]. The prepared solutions were transferred to a $30-\mathrm{mL}$ syringe with a capillary tip $(18 \mathrm{G})$. The syringe was then placed in a KD scientific syringe pump (Model 100). The solution was ejected onto an aluminum foil-covered collector. Electric power was applied using a high-voltage power supply (NT-PS-25K, NTSEE Co., Korea) at $15 \mathrm{kV}$. Please refer to our previous work for more details [16]. Before the electrospun fibers were carbonized, a stabilization step was performed to convert the thermoplastic polymer, which may soften and melt at high temperatures, into a thermosetting polymer. The stabilization step was then performed at $573 \mathrm{~K}$ for $4 \mathrm{~h}$ in air. The stabilized electrospun samples were heat-treated in a nitrogen atmosphere at $1323 \mathrm{~K}$ under the following conditions: a heating rate of $10 \mathrm{~K} / \mathrm{min}$, a holding time of $1 \mathrm{~h}$ and a nitrogen feeding rate of $100 \mathrm{~mL} / \mathrm{h}$ [17]. The resultant non-woven carbon fibers with $0,10,25$, and $50 \% \mathrm{MgO}$ were denoted as RF, ACFM10, ACFM25, and ACFM50, respectively. The $\mathrm{MgO}$ powders were removed from these fibers by immersing non-woven fibers in $1.5 \mathrm{M} \mathrm{HCl}$ at room temperature for $24 \mathrm{~h}$.

\subsection{Preparation of the gas sensor}

The prepared fibers $(0.05 \mathrm{~g})$ were dispersed in acetone $(2.5 \mathrm{~g}$, Samchun Chemical Co., Korea, 99.5\%) and then sonicated for 25 min for uniform spreading in the acetone. This dispersed solution $(0.01 \mathrm{~g})$ was dropped onto a silicon wafer with Pt through the use of a micro-pipette (Ovation pipette, Vistalab, $1000 \mu \mathrm{m}$ ) and was then spin-coated (spin coater, ACE-200) at $1000 \mathrm{rpm}$ for 5 min. The wafer was mounted on the end of silver wires $(100 \mu \mathrm{m}$ in diameter and $4 \mathrm{~cm}$ in length) and fixed using silver paste. The wafer was heated on a hot plate at $373 \mathrm{~K}$ for $10 \mathrm{~min}$ to remove any impurities in the electrode. Thus, the gas sensor electrode thickness of the deposited materials on silicon wafer was $16 \pm 1 \mu \mathrm{m}$

\subsection{Characterization of the prepared samples}

Viscosity measurements were performed using a Brookfield programmable digital viscometer (DV-II+PRO, Brookfield Engineering, USA). The device consists of a spindle (RV2-4) and a cooling jacket with a temperature control module (FTKY3). In order to investigate the surface morphology of the resultant samples, scanning electron microscope (SEM) images were obtained using a field-emission SEM (FE-SEM, Hitachi, S-5500). The textural properties of the resultant samples (RF, ACFM10, ACFM25, and ACFM50) were investigated before making the electrode of the gas sensor. The samples were degassed at 423 $\mathrm{K}$ for $3 \mathrm{~h}$. Nitrogen adsorption was then performed at $77 \mathrm{~K}$ with a Brunauer-Emmett-Teller (BET) apparatus (Micromeritics ASAP 2020) to investigate the specific surface area (SSA), the total pore volume, the pore size distribution, and the micropore fraction of each sample were assessed. 


\subsection{Measurement of the gas sensitivity}

The experimental setup employed a programmable electrometer (Keithley 6514) to evaluate the gassensing properties of the prepared electrode samples. Sensors were positioned in a thermally isolated stainless steel chamber and a sealed test cell $(1500 \mathrm{~mL}$ volume) endowed with a gas inlet and outlet. The prepared gas sensor sample was placed in the sealed chamber under a vacuum at a pressure of $1 \times 10^{-3}$ torr. Initially, nitrogen gas was injected into the chamber to stabilize the electrical resistance. The test NO gas was diluted with $\mathrm{N}_{2}$ to obtain a molar concentration of $1000 \mathrm{ppm}$. $\mathrm{N}_{2}$ gas was used as a carrier gas to control the gas concentrations further. The mixture gas, which had a concentration of 50 ppm $\mathrm{NO}$ in $\mathrm{N}_{2}$, was injected into the chamber at a constant total flow rate of $250 \mathrm{sccm}$. The change in the electrical resistance was measured at $298 \pm 1 \mathrm{~K}$. After the electrical resistance was stabilized under the NO gas, the injection of NO gas was turned off and the recovery of the electrical resistance was observed. The gas-feeding rate was kept constant at $250 \mathrm{sccm}$ throughout the experiment. The sensitivity (S) of the sensor is defined by the percentile resistance change when the sensor is exposed to a gas, as follows

$$
\text { Sensitivity }=\mathrm{S}(\%)=\frac{R_{o}-R_{g}}{R_{g}} \times 100
$$

Here, $R_{0}$ is the resistance of the sensor in $\mathrm{N}_{2}$ gas and $\mathrm{R}_{\mathrm{g}}$ is the resistance of sensor under the test gas (NO) [16]

\section{Results and Discussion}

\subsection{Morphology analysis of non-woven fibers}

Fig. 1 shows the morphologies of the electrospun carbon fibers that were prepared with different ratios of $\mathrm{MgO}(0,10,25$, and 50 $\mathrm{wt} \%$, based on the amount of PAN). Some beads were detected on the fibers produced in the absence of the $\mathrm{MgO}$. These beads were most likely the result of the pitch not completely dissolved in the THF solvent due to aggregation and the high molecular weight of the pitch molecules. However, the number of beads on the carbon fibers that were produced in the absence of the $\mathrm{MgO}$ was very small relative to number on the $\mathrm{MgO}$-containing fibers. Fig. lb-d shows that the number of beads on the porous carbon fibers produced with the $\mathrm{MgO}$ increased with an increase in the percent $\mathrm{MgO}$ due to the aggregation of the pitch and the $\mathrm{MgO}$ powder. In addition, the quality of the electrospun fibers is related to the instability of the jet of

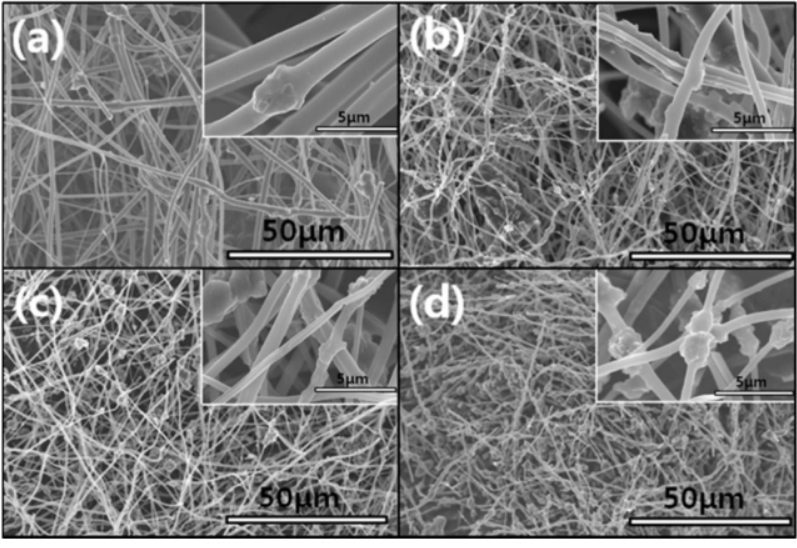

Fig. 1. Scanning electron microscope images of nanoporous nonwoven carbon fibers: (a) RF, (b) ACFM10, (c) ACFM25, and (d) ACFM50.

polymer solution and the change in the breakpoint of the surface tension of the Taylor cone. The changes in the concentrations of the $\mathrm{PAN}$, pitch and $\mathrm{MgO}$ in the polymer resulted in changes in the solution viscosity. The viscosity change according to the content of $\mathrm{MgO}$ powder is shown in Table 1 . The surface tension coefficient depends on the polymer, the solvent, and the viscosity. Consequently, beads formed in these samples due to surface tension [18]

The average diameter of each non-woven carbon fiber decreased from 2.5 to $1.0 \mu \mathrm{m}$ with an increase in the content of $\mathrm{MgO}$ powders added to the pitch/PAN precursor solution (Fig. 1). In addition, more beads were observed with an increase in the content of $\mathrm{MgO}$ powders added. This unique form, beads strung by fibers, can be attributed to the aggregated $\mathrm{MgO}$ powders added to the pitch/PAN precursor solution. In this case, the fiber seems to be formed between electrospinning and electrospraying. The $\mathrm{MgO}$ powders are usually placed inside the PAN-based electrospun fiber rather than on the surface of the fiber [19]; the aggregation of $\mathrm{MgO}$ powders induced the formation of bead, inducing electrospraying. On the other hand, the pitch/PAN mixture forms fibers by electrospinning between the bead formations. Based on the numbers of beads and the thickness of the fibers, it seems that as more beads formed, thinner fibers also formed.

\subsection{Textural properties}

Fig. 2 shows the nitrogen adsorption isotherms for the carbon fibers that were produced in this study. The pore textures of the non-woven carbon fibers changed as a result of the template method that was used. The sample produced without the $\mathrm{MgO}$

Table 1. Viscosity of the spinning solution and textural properties of the activated samples

\begin{tabular}{ccccccc} 
& Viscosity $(\mathrm{cP})$ & $\mathrm{SSA}\left(\mathrm{m}^{2} / \mathrm{g}\right)$ & $\mathrm{V}_{\mathrm{T}}\left(\mathrm{cm}^{3} / \mathrm{g}\right)$ & $\mathrm{V}_{\mathrm{Mi}}\left(\mathrm{cm}^{3} / \mathrm{g}\right)$ & $\mathrm{F}_{\mathrm{M} \text { i }}(\%)$ & Average diameter $(\mu \mathrm{m})$ \\
\hline RF & $1048( \pm 2)$ & 2 & - & - & - & $2.5( \pm 0.2)$ \\
\hline ACFM10 & $1170( \pm 2)$ & 422.1 & 0.287 & 0.102 & 35.5 & $1.5( \pm 0.3)$ \\
\hline ACFM25 & $1350( \pm 2)$ & 658.9 & 0.349 & 0.096 & 27.8 & $1.2( \pm 0.3)$ \\
\hline ACFM50 & $1754( \pm 2)$ & 763.2 & 0.584 & 0.060 & 10.3 & $1.0( \pm 0.4)$ \\
\hline
\end{tabular}

SSA: specific surface area, $\mathrm{V}_{\mathrm{T}}$ : total pore volume, $\mathrm{V}_{\mathrm{Mi}}$ : micropore volume, $\mathrm{F}_{\mathrm{Mi}}$ : fraction of micropore volume. 


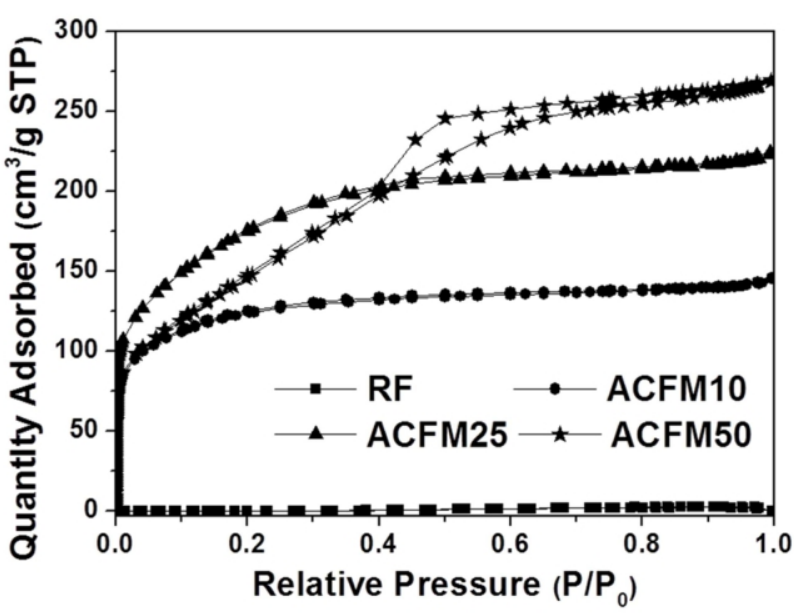

Fig. 2. Nitrogen adsorption isotherms of the nanoporous non-woven carbon fibers in this study.

powders $(\mathrm{RF})$ showed no change during the adsorption of nitrogen, which indicated that this sample was non-porous. However, the nitrogen absorption analysis of the samples prepared using this method (ACFM10, ACFM25 and ACFM 50) showed that a greater increase was apparent as the samples were prepared with increasing amounts of $\mathrm{MgO}$. This finding indicated that ACFM10 and ACFM25, which exhibited an inflection point at approximately $0.01 \mathrm{P} / \mathrm{P}_{0}$, are typical type I materials; therefore, these materials are microporous non-woven carbon fibers. In general, an increase in the nitrogen adsorption isotherm curve in porous materials is indicative of the creation of a micropore structure (less than $0.01 \mathrm{P} / \mathrm{P}_{0}$ ) or a mesopore structure (over 0.01 $\mathrm{P} / \mathrm{P}_{0}$ ) [6]. However, the curve obtained for ACFM50 was a different type of adsorption isotherm curve. The ACFM50 sample showed type VI behavior and a hysteresis loop close to the International Union of Pure and Applied Chemistry (IUPAC) H2 loop [20]. Hysteresis loops are caused by the presence of aggregated powders in the non-woven carbon fibers; therefore, in the case of ACFM50, the hysteresis loop indicates the presence of aggregated $\mathrm{MgO}$ powders due to the large amount of $\mathrm{MgO}$ that was used. Nano-sized powders (less than $100 \mathrm{~nm}$ in diameter), such as metal oxide, cannot be easily dispersed due to the surface interactions between the particles. These interactions contribute to the enhancement and further induction of the aggregation of the $\mathrm{MgO}$ particles. The increase in the concentration of $\mathrm{MgO}$ would therefore lead to an increase in the aggregation of the $\mathrm{MgO}$ particles [21]. Consequentially, the excess amount of $\mathrm{MgO}$ in the pitch/PAN/DMF solution that was used for the production of the ACFM50 sample resulted in the formation of clusters, and the subsequent removal of these clusters led to the formation of a complicated pore structure, including the presence of ink bottle pores. The presence of the adsorption/desorption hysteresis loop was caused by the presence of an ink bottle type of pore. Hence, ACFM50 has a mesoporous and microporous nature (micropore $<2 \mathrm{~nm}, 2 \mathrm{~nm}<$ mesopore $<50 \mathrm{~nm}, 50 \mathrm{~nm}<$ macropore). Fig. 3 explains this result in more detail by showing a comparison of the pore size distributions, which were calculated using density functional theory, of the samples prepared using the template method. Fig. 3 shows that the numbers of micropores and meso-

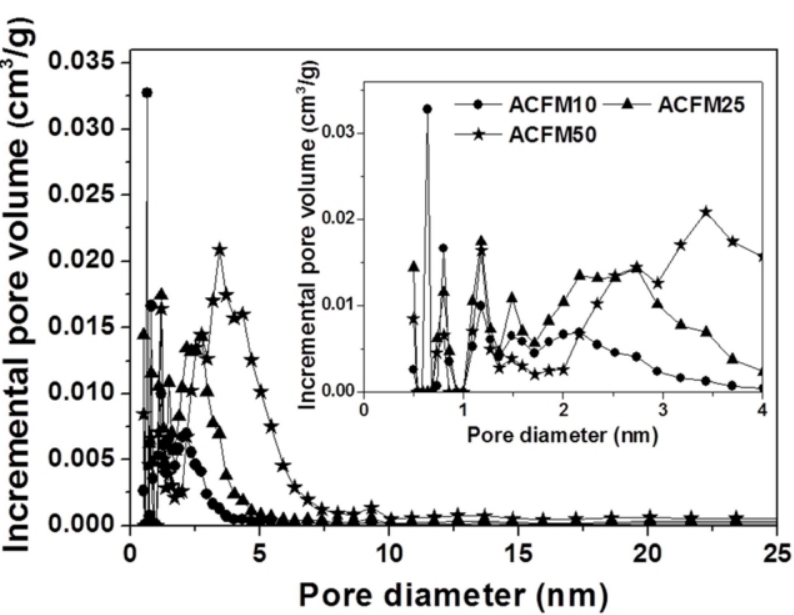

Fig. 3. Pore-size distributions of samples used in this study. The inset illustration shows the numbers of micropores and small mesopores (approximately $2-4 \mathrm{~nm}$ in size) in the different samples.

pores were greater in the samples that were produced using the template method than in the non-template sample.

Detailed information pertaining to the textural properties of the samples is also presented in Table 1. The SSA increased from 2 to $763.2 \mathrm{~m}^{2} / \mathrm{g}$ when using the template method. The micropore volume fractions of the pitch/PAN carbon fibers that were produced using the template method were in the range of 10 to $35 \%$ This fraction increased with an increase in the $\mathrm{MgO}$ content $(\mathrm{RF}$ $<$ ACFM10). However, the other porous fibers (ACFM25 and ACFM50) did not follow this trend. Because increases in the $\mathrm{MgO}$ content used in the production of the fibers can lead to an increase in the amount and size distribution of $\mathrm{MgO}$ aggregates, these samples exhibited a more complicated pore structure that was composed of micropores and mesopores; therefore, the measurement of the micropore fraction was not applicable.

\subsection{Gas sensing by resistive response}

The resistive response of an electrode prepared from non-woven carbon fibers is shown as a function of the time of exposure to NO gas in Fig. 4a. The RF sample exhibited a $0.1 \%$ resistive response due to the presence of inactive $\mathrm{NO}$ gas adsorption sites and due to the non-porous nature of the material (Fig. 2, Table 1) The development of a porous structure increased the NO gas-sensing capability by approximately $12.5 \%$, as shown by the response measured for the ACFM25 sample. This result implies that the porous structure that is generated through the use of the template method effectively increased the number of gas adsorption sites The electrical resistance in the ACFM10, ACFM25 and ACFM50 samples significantly decreased by approximately $12 \%, 12.5 \%$, and $7.7 \%$, respectively, within $3 \mathrm{~min}$. This result is mainly due to the fact that the NO gas molecules were absorbed in the mesopores and micropores of the carbon fibers. Previous studies in this field have reported that $\mathrm{NO}$ gas molecules are quickly adsorbed in narrow micropores. In addition, the adsorption of $\mathrm{NO}$ gas in micropores is faster than the NO gas adsorption in mesopores [22,23]. As shown in Fig. 4a, ACFM10 has a faster response time than the other samples, which is consistent with the fact that this sample 

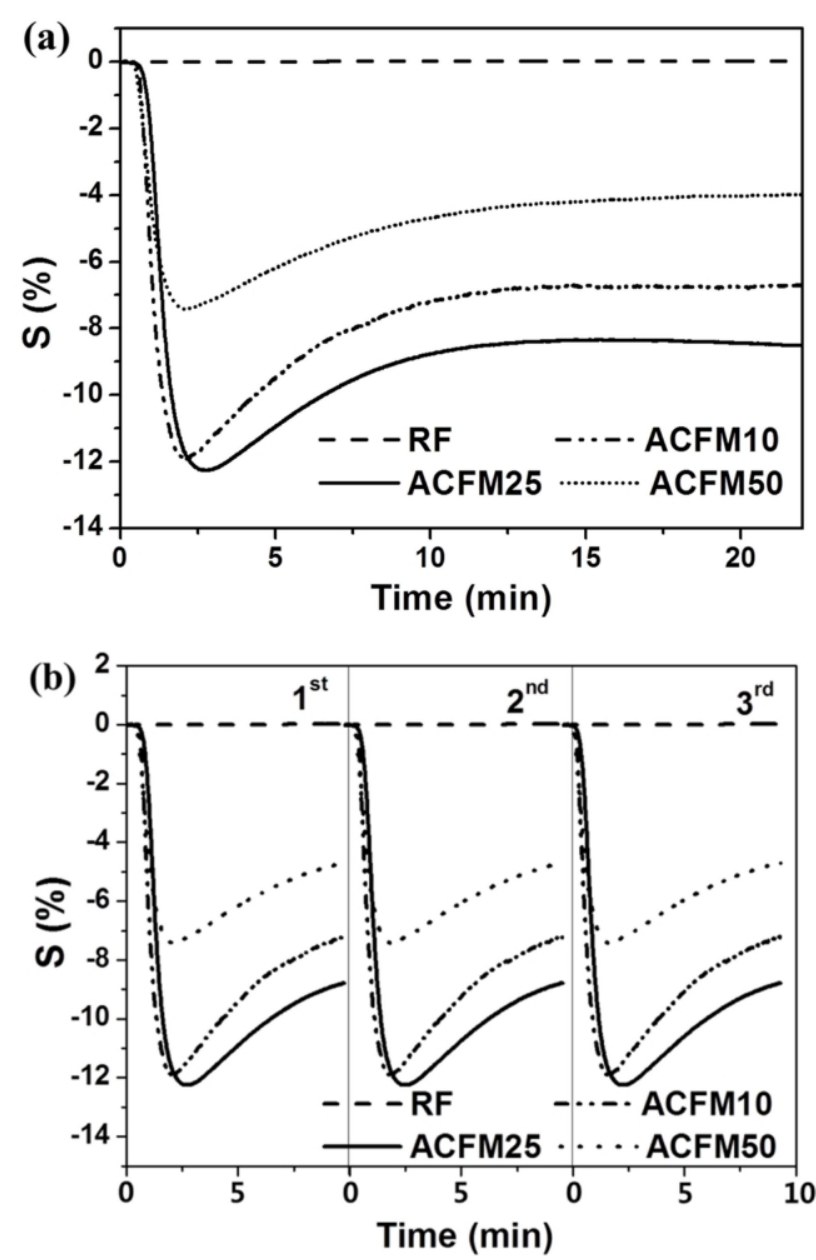

Fig. 4. Resistive response (a) and recovery property (b) according to the time for NO gas sensing.

has the largest micropore volume (Table 1). However, because ACFM25 has an adequate SSA and micropore volume for NO gas adsorption, this sample exhibited the lowest resistance. In addition, ACFM10 and ACFM25 exhibited very similar gas sensitivity levels and response times. Therefore, it is very important to optimize the micropore volume fraction and the SSA in porous carbon materials. The electrical sensitivity of these materials was improved by creating a micro-scale pore structure with an adequate SSA.

Fig. $4 \mathrm{~b}$ presents the gas sensor's recovery property in all samples. Perfect reproducibility was observed in all cases, which is attributed to the excellent gas desorption properties of the carbon materials during the recovery process, which was characterized by a low degassing pressure and a high temperature. This excellent desorption is one of the general advantages of porous carbon materials [22].

\section{Conclusions}

A high-performance NO gas sensor was prepared from nonwoven carbon fibers using electrospun pitch/PAN-based fiber embedded $\mathrm{MgO}$ as a pore-forming agent. The $\mathrm{MgO}$ powders influenced the polymer solvent viscosity and the SSA. An increase in the amount of $\mathrm{MgO}$ powders in the pitch/PAN precursor solvents led to the formation of an increased amount of beaded fibers and a greater SSA. The pore structure that resulted from the use of the template method enabled the efficient adsorption of NO gas due to the increased SSA and micropore volume, which resulted in a gas sensor with high sensitivity. Overall, the sensing ability for $\mathrm{NO}$ gas was significantly improved through the use of $\mathrm{MgO}$ powders in the preparation of the carbon fibers.

\section{Acknowledgments}

This work was supported by a grant from the institutional program of the Korea Institute of Science and Technology (KIST).

\section{References}

[1] Wang SH, Kuo SH, Shen CY. A nitric oxide gas sensor based on Rayleigh surface acoustic wave resonator for room temperature operation. Sensors Actuators B: Chem, 156, 668 (2011). http:// dx. doi. org/10.1016/j.snb.2011.02.016.

[2] Do JS, Wu KJ, Tsai ML. Amperometric NO gas sensor in the presence of diffusion barrier: selectivity, mass transfer of $\mathrm{NO}$ and effect of temperature. Sensors Actuators B: Chem, 86, 98 (2002). http:/ dx. doi. org/10.1016/s0925-4005(02)00154-5.

[3] Do JS, Wu KJ. Amperometric nitric oxide gas sensor: preparation of $\mathrm{Au} / \mathrm{SPE}$ and sensing behavior. Sensors Actuators B: Chem, 67, 209 (2000). http://dx.doi.org/10.1016/s0925-4005(00)00418-4

[4] Wetchakun K, Samerjai T, Tamaekong N, Liewhiran C, Siriwong C, Kruefu V, Wisitsoraat A, Tuantranont A, Phanichphant S. Semiconducting metal oxides as sensors for env ironmentally hazardous gases. Sensors Actuators B: Chem, 160, 580 (2011). http://dx. doi. org/10.1016/j. snb.2011.08.032.

[5] Lin CY, Chen JG, Feng WY, Lin CW, Huang JW, Tunney JJ, Ho KC. Using a $\mathrm{TiO}_{2} / \mathrm{ZnO}$ double-layer film for improving the sensing performance of $\mathrm{ZnO}$ based NO gas sensor. Sensors Actuators B: Chem, 157, 361 (2011). http://dx.doi.org/10.1016/j. snb. 2011.04 .056

[6] Im JS, Kang SC, Bai BC, Bae TS, In SJ, Jeong E, Lee SH, Lee YS Thermal fluorination effects on carbon nanotubes for preparation of a high-performance gas sensor. Carbon, 49, 2235 (2011). http:// dx. doi.org/10.1016/j.carbon.2011.01.054

[7] Choi JK, Hwang IS, Kim SJ, Park JS, Park SS, Jeong U, Kang YC, Lee JH. Design of selective gas sensors using electrospun Pddoped $\mathrm{SnO}_{2}$ hollow nanofibers. Sensors Actuators B: Chem, 150, 191 (2010). http://dx.doi.org/10.1016/j.snb.2010.07.013.

[8] Park Y, Dong KY, Lee J, Choi J, Bae GN, Ju BK. Development of an ozone gas sensor using single-walled carbon nanotubes. Sensors Actuators B: Chem, 140, 407 (2009). http://dx.doi.org/10.1016/j. snb.2009.04.055

[9] Kinoshita K. Carbon: electrochemical and physicochemical properties, Wiley, New York (1988)

[10] Im JS, Kang SC, Lee SH, Lee YS. Improved gas sensing of electrospun carbon fibers based on pore structure, conductivity and surface modification. Carbon, 48, 2573 (2010). http://dx.doi. org/10.1016/j. carbon. 2010.03.045

[11] Greene ML, Schwartz RW, Treleaven JW. Short residence time graphitization of mesophase pitch-based carbon fibers. Carbon, $\mathbf{4 0}$, 
1217 (2002). http://dx. doi.org/10.1016/s0008-6223(01)00301-3

[12] Kim BH, Bui NN, Yang KS, Cruz ME, Ferraris JP. Electrochemical properties of activated polyacrylonitrile/pitch carbon fibers produced using electrospinning. Bull Korean Chem Soc, 30, 1967 (2009).

[13] Inagaki M, Kobayashi S, Kojin F, Tanaka N, Morishita T, Tryba B Pore structure of carbons coated on ceramic particles. Carbon, $\mathbf{4 2}$, 3153 (2004). http://dx. doi.org/10.1016/j.carbon.2004.07.029.

[14] Morishita T, Tsumura T, Toyoda M, Przepiorski J, Morawski AW, Konno H, Inagaki M. A review of the control of pore structure in MgO-templated nanoporous carbons. Carbon, 48, 2690 (2010). http://dx.doi.org/10.1016/j. carbon. 2010.03.064.

[15] Kim BH, Yang KS, Kim YA, Kim YJ, An B, Oshida K. Solvent-induced porosity control of carbon nanofiber webs for supercapacitor. J Power Sources, 196, 10496 (2011). http://dx. doi.org/10.1016/j. jpowsour.2011.08.088

[16] Im JS, Kang SC, Lee YS. Improved sensitivity of an NO gas sensor by chemical activation of electrospun carbon fibers. Carbon Lett, 12, 21 (2011).

[17] Im JS, Jang JS, Lee YS. Synthesis and characterization of mesoporous electrospun carbon fibers derived from silica template. J Ind Eng Chem, 15, 914 (2009). http://dx.doi.org/10.1016/j.jiec 2009.09.024.

[18] Fong H, Chun I, Reneker DH. Beaded nanofibers formed dur- ing electrospinning. Polymer, 40, 4585 (1999). http://dx.doi.org/ 10.1016/S0032-3861(99)00068-3.

[19] Im JS, Park SJ, Kim TJ, Lee YS. Hydrogen storage evaluation based on investigations of the catalytic properties of metal/metal oxides in electrospun carbon fibers. Int J Hydrogen Energy, 34, 3382 (2009). http://dx.doi.org/10.1016/j. ijhydene.2009.02.047.

[20] Sing KSW, Everett DH, Haul RAW, Moscou L, Pierotti RA, Rouquerol J, Siemieniewska T. Reporting physisorption data for gas/ solid systems with special reference to the determination of surface area and porosity. Pure Appl Chem, 57, 603 (1985). http://dx. doi. org/10.1351/pac198557040603.

[21] Ng LY, MohammadAW, Leo CP, Hilal N. Polymeric membranes incorporated with metal/metal oxide nanoparticles: a comprehensive review. Desalination (2010). In press. http://dx.doi.org/10.1016/j. desal.2010.11.033.

[22] Kang SC, Im JS, Lee SH, Bae TS, Lee YS. High-sensitivity gas sensor using electrically conductive and porosity-developed carbon nanofiber. Colloids Surf Physicochem Eng Aspects, 384, 297 (2011). http://dx. doi. org/10.1016/j.colsurfa.2011.04.001

[23] Liao L, Zheng M, Zhang Z, Yan B, Chang X, Ji G, Shen Z, Wu T, Cao J, Zhang J, Gong H, Cao J, Yu T. The characterization and application of p-type semiconducting mesoporous carbon nanofibers. Carbon, 47, 1841 (2009). http://dx.doi.org/10.1016/j.carbon.2009.03.029. 